\title{
POTENTIAL USE OF INDIGENOUS RHIZOBIAL BIOFERTILIZERS FOR CULTIVATION OF GROUNDNUT PLANT - A SHORT MINI REVIEW
}

\author{
V. Nithyakalyani \\ Assistant Professor, Department of Microbiology \\ Dr. MGR Janaki College of Arts and Science for Women, \\ Chennai, Tamil Nadu, India
}

\begin{abstract}
Soil, an unpredictable environment may not produce intended results of plant growth promotion. Moreover, the effect of PGPR in crop productivity varies under laboratory, greenhouse and field trials. Various abiotic and biotic stress factors influence the effectiveness and survival of PGPR since unfavorable growth conditions in the field are expected in the normal functioning system of agriculture. Unlike local strains, foreign strains may not be adapted to the local soil, climatic conditions or prevailing environmental status in the field. For a promising path forward, a rational strategy of identifying local native rhizobial strains with high SNF properties is the timely need. Specific identification of potent isolates based on "additive hypothesis" with traits of phosphate solubilization, dinitrogen fixation, ACC deaminase, antifungal activity, IAA and siderophore biosynthesis and stress tolerance would be highly valuable. PGPR applications under both natural and controlled soil environments has significantly increased the yield of crops, which makes PGPR to be advantageous as a means of promoting plant growth. As a technology readily accessible by the farmers, further research contributing to investigation on PGPR'S capacity to mitigate various stress factors for the successful use of rhizobacteria with varied applications, such as phytoremediation, bio fertilization is the need of the hour to establish the native potent strains in the already existing community of soil microorganisms.
\end{abstract}

Keywords:

Rhizobium, BNF, Native strains, PGPR, Stress tolerance, Groundnut cultivation, Tamil Nadu

\section{INTRODUCTION}

The world's population is set to grow considerably over the coming years. Over the next four decades, the world's population is forecast to increase by two billion people to exceed nine billion people by 2050 (Godfray et al., 2010). Recent FAO estimates indicate that to meet the projected demand, global agricultural production will have to increase by 60 percent. Agriculture plays a vital role in India's economy (Alexandratos, 2012). The Indian food industry is poised for huge growth, increasing its contribution to world food trade. Thirty-two percent of India's total food market is contributed by the food processing industry making it one of the largest in the country bagging the $5^{\text {th }}$ rank in terms of production, consumption, export and expected growth. India aspires to double its farm income by 2022 . Intensification of production can be associated with significant dismissive environmental effects, including groundwater pollution, soil erosion and a loss in biodiversity. A large proportion of land area in India shows continuous soil degradation due to overgrazing, expanding population and deforestation.

\section{CHALLENGES FACED IN AGRICULTURE SECTOR}

The greatest challenge of today's agriculture is to meet the feed demands of doubling growing population and simultaneously restore the natural resources. Uncontrolled population growth in developing countries accelerated the imbalance between human needs and sustainable use of land. Conventional agriculture practices and the growing population led to an increasing demand of chemical fertilizers (Mahanty et al., 2017). Though chemical 
fertilizers enhanced the production and productivity of crops, the increased use of pesticides posed many environmental and health problems. The usage of chemical fertilizers and pesticides for a long period of time has unfavorable noxious effect on the production potential of the land and indirectly the consumers of the products. Chemical fertilizers contain pestilential components like heavy metals, inorganic acids, organic pollutants which has a perennial impact on the richness of the soil and questions the importance of soil management practices for sustainable agriculture practices $(\mathrm{Li}$ et al., 2008). Bhardwaj et al., 2014 realized the importance of useful aspects of biofertilizers and implementation of its application to modern agricultural practices. To overcome the problem of chemical fertilizers and to improve the declining productivity, the dependability ratio on chemical fertilizers must be reduced and replaced with biofertilizers.

\section{POTENTIAL SIGNIFICANCE OF MICROBIOMES IN AGRICULTURE PRACTICES}

Use of microbial agents for enhanced agricultural yield, improvement of soil and plant health had been practiced for centuries. Applying seeds mixed with microbial bio-inoculants for legume inoculation was initiated at the end of $19^{\text {th }}$ century. The search for microorganisms that improve soil fertility and enhance plant nutrition has continued to attract attention due to the increasing cost of fertilizers and some of their negative environmental impacts. To ensure bio-safety, efforts have been channelized to produce enriched foods by using organic fertilizers auxiliary to chemical synthetic fertilizers. Organic farming, an innocuous and robust practice assures food safety and soil fertility (Araujo et al., 2008 \& Megali et al., 2014). Organic farming has a positive influence on microbial biomass, thereby promoting changes in soil quality. The ecofriendly approach of organic farming promotes the usage of biofertilizers, an efficient microbial community of PGPRs, endo and ectomycorrhizal fungi, cyanobacteria, actinomycetes and other useful microbial flora which possess an array of beneficial properties including biological nitrogen fixation, solubilization of minerals, release of phytohormones, suppression of plant pathogens and biodegradation of organic matter in the soil (Singh et al., 2011).

Rhizobium, a gram negative non sporing, aerobic, motile bacilli inhabit the root nodules of most leguminous crops characterized by their distinctive aptness to colonize root hairs of legumes and effectuate nitrogen fixation. Rhizobium constitute intimate symbiotic relationships with legumes and manifest a response chemotactically to signal molecules of flavonoids exempted by legume host plants which induce the nodulation expression system (nod) in rhizobia to provoke cell division in roots to form nodules (Matiru \& Dakora, 2004; Lhuissier et al., 2001).

\section{PLANT GROWTH PROMOTING TRAITS OF RHIZOBIA - DIRECT PROMOTION OF PLANT GROWTH}

Rhizobia explicitly have a direct impact on the growth and development of plants by fixing atmospheric nitrogen, solubilizing phosphorous, production of phytohormones or by producing siderophores. The co-existence of legume rhizobia enables the induction of nodules for effective BNF, an energy expensive process. The major process through which the atmospheric nitrogen is converted to plant usable organic nitrogen contributing a quantitative impact on nitrogen cycle is biological nitrogen fixation (BNF). Legume rhizobia (Rhizobium/Bradyrhizobium/Mesorhizobium)

symbiosis, a cheaper source of nitrogen and an effective agronomic practice ensures adequate supply of nitrogen than the application of commercial chemical fertilizer. The nitrogen fixation efficiency of legumes depends on the host genotype, rhizobial efficiency, soil conditions, and climatic factors. Lindstrom et al., 1990 highlighted the predominance of Rhizobium in nodules for 15 years after initial inoculation establishes the proven concept of rhizobial inoculants for enhanced nitrogen fixation. Rhizobium are effective colonizers persisting in soil for many years in the absence of their host (Sanginga et al., 1994). Researchers have confirmed the potential phosphate solubilizing capacity of rhizobia (Vessey, 2003). Through phosphate solubilization, the phosphorous accumulated in the soil is supplied to the plants by the intervention of rhizobia, including $R$. leguminosarum, $R$. meliloti, M. mediterraneum, Bradyrhizobium and B. japonicum which are considered as potential phosphate solubilizers (AbdAlla, 1994).

Phytohormones are the substances that vitalize plant growth at lower/equal to micro molar concentrations. Both nodulating and non-nodulating strains of Rhizobium leguminosarum produce indole3-acetic acid, auxins, cytokinins, Abscisic acid, ACC deaminase, lipo-chitooligosaccharide, EPS and siderophores that promote plant growth (Parthiban et 
International Journal of Engineering Applied Sciences and Technology, 2019

Vol. 4, Issue 4, ISSN No. 2455-2143, Pages 141-146

Published Online August 2019 in IJEAST (http://www.ijeast.com)

al.,2016; Sagolshemcha et al., 2017; Kannahi \& Senbagam, 2014; Miransari \& Smith, 2009; Atzorn et al., 1988; Glick, 2012).

\section{INDIRECT GROWTH PROMOTIONS OF RHIZOBIA}

Rhizobia adapts to serve as plant growth accelerators containing biocontrol properties and induce systemic resistance towards phytopathogens and insect pests. Many strains of rhizobia have reported to contain biocontrol properties. Production of antibiotics (Bardin et al., 2004; Chandra et al., 2007) and low molecular weight metabolites like Hydrogen Cyanide (Bhattacharyya \& Jha, 2012) and enzymes such as chitinases, protease and lipase (Ozkoc \& Deliveli, 2001; Siddiqui \& Mahmood, 2001) are successful mechanisms of strains of $R$. leguminosarum, $R$. meliloti, $R$. trifolii $S$. meliloti and B. japonicum to compete against plant pathogens. The antagonism of rhizobial strains against plant pathogenic microorganisms have been elaborated through the findings of Bhagat et al., 2014, Kucuk, 2013 \& Subhani et al., 2013. The induction of systemic resistance in plants by rhizobial strains through production of bio stimulatory agents have been documented by Mishra et al., 2006 and Lugtenberg \& Kamilova, 2009.

\section{RHIZOBIAL BIOFERTILIZERS RELEVANCE TO TOLERANCE AGAINST ENVIRONMENTAL STRESS}

A greater limitation is caused by abiotic and biotic stresses on the productivity of crops. These vary from soil moisture deficiency, drought, extremes of temperature, soil salinity, soil $\mathrm{pH}$, accumulation of heavy metals to overdoses of fertilizers and pesticides. An insight on the influence of these factors on the driving force of BNF, the endurance and infectivity rate of rhizobia helps in identifying rhizobial strains with resistance to environmental stresses which is of paramount importance in the research concerning their potentiality to enhance plant yield.

Salinity, one of the major production constraints employ deleterious effect on the growth of rhizobia, accompanied by impeding nodule development (Brigido et al., 2012) and BNF process by alleviating the nodule metabolomics and leghemoglobin content. Rhizobial species vary in their salt sensitivity. A strain of Rhizobium japonicum USDA191 which is more resilient to salt than the strain USDA110 has been identified (Yelton et al., 1983). Mesorhizobium strains are more vulnerable to salt stress than Rhizobium, Sinorhizobium or Bradyrhizobium strains. Alleviation of salinity problem could be accomplished by identifying salt tolerant strains sustaining under salinity stress and promoting plant growth as stated by Bertrand et al., 2015 \& Qu et al., 2016.

High temperature exhibits adverse effects on survival of rhizobia and nodulation capacity. As a defensive mechanism, rhizobia synthesize HSP's which contribute to heat tolerance of rhizobial cells without disrupting the integrity of cell membrane (Yura, 2006; Alexandre \& Oliveira, 2013). Alkaline or acidic soil influences the survival of rhizobia that turns rhizobia legume symbiosis into a fiasco (Richardson et al., 1988). With rapid development of industrialization and urbanization, heavy metal pollution in soil is greatly increasing and poses negative impact on agricultural practices. It is mandatory to isolate the native rhizobial strains from heavy metals contaminated soils, to identify the potential of rhizobia-legume symbiosis of specific strain for the remediation of the affected area, since, heavy metals can exert a selective pressure on the microbes rendering them tolerant. Bacteriostatic or bactericidal effects of pesticides is natural when the chemicals are applied to soil, foliage or coated with seeds. Mathur et al., 1999 stated that the alteration of plant's root and shoot architecture, root sites for rhizobial infection, ammonification process and reduction in the count of rhizobial population and physiological rate are the possible outcome of pesticide accumulation in soil and accumulation of high agrochemical concentration is more cataclysmic to beneficial microbes as compared to less concentration (Aynalem \& Assefa, 2017).

Research on isolating, identifying and characterizing resistant rhizobia needs to be vigorously pursued as such chemicals when used in conjunction with microbial inoculants exert a negative effect on both the partners. Detrimental effects of fungicides and insecticides have been documented by various researchers. The deleterious effects of fungicides on biological nitrogen fixation can directly affect the nodulation status and activity (Bikrol et al., 2005). Insecticides especially Carbamate insecticides such as Carbaryl (1-naphthyl $\mathrm{N}$-methyl carbamate) are broad-spectrum agents that are considered hazardous and constitute the major proportion of agricultural pesticides in today's agricultural industry. The response of different 


\section{International Journal of Engineering Applied Sciences and Technology, 2019}

Vol. 4, Issue 4, ISSN No. 2455-2143, Pages 141-146

Published Online August 2019 in IJEAST (http://www.ijeast.com)

rhizobia to insecticides is of great concern since symbiotic nitrogen fixation relies on the effective interaction between the host and rhizobia. In order to meet the world's food demand, it is imperative for sustainable agricultural productivity to screen and assess the potentiality of rhizobial microbes intended for agricultural application.

\section{GROUNDNUT CULTIVATION AND CONSTRAINTS}

The prime source of edible oil and vegetable protein are the groundnuts (Peanut). It is one of the significant crop cultivated in India around six million hectare contributing to a yearly production of seven million tons. Gujarat, Andhra Pradesh, Tamil Nadu, Karnataka, Maharashtra, Madhya Pradesh, Uttar Pradesh and Rajasthan are important groundnut growing areas in India. Tamil Nadu stands as a leading state in the production of groundnut as it is endowed with a comfortable climatic condition favoring its growth. This legume grows in seasons like rainy, post-rainy and summer. This legume productivity mainly depends on the requirement of nitrogen. Most of the nitrogen requirement of the plant is facilitated through BNF process. In a state like Tamil Nadu, where the groundnut cultivation is mostly in marginal lands of soil deficit in organic matter or with minimal nutrient supply, the nutrient demands of the plant should be met by applying biofertilizers of potential significance. Application of stress tolerant plant growth promoting competitive native rhizobial promising strains nodulate the plants effectively.

\section{CONCLUSION}

Rhizobial BNF in legumes is cataloged, yet, studies on appropriate understanding of physiology and selecting efficient isolates for promotion of plant growth, with heavy metals and pesticides detoxification which controls a range of fungal pathogens have to be identified which suits the prevailing soil and environmental conditions to achieve a successful interaction. Moreover, the use of commercial rhizobial inoculants to improve the performance of the crop is limited due to the high cost of the cultures for preparing the inoculum, availability of limited information on inoculation benefits, and poor performance of the strains due to lack of adaptation to local agro climatic conditions or negative microbial interactions. Besides, the availability of highly effective native rhizobia in field soils has not been exploited. Research on elucidating the potential of native rhizobial isolates to improve BNF and growth of groundnut by testing the hypotheses that different native rhizobial strains nodulating groundnut crops varies in their nitrogen fixation efficiency and effectiveness of plant growth promotion. The above aim could be fulfilled by comparing the effectiveness of native rhizobia isolates versus commercial strains and also by determining the co-inoculation effect of rhizobia species diversity by mixing commercial strain and native strains on the growth and yield of plant. To gain the desired effects and improved crop yield, the end user should identify stress tolerant rhizobial strains with added characteristic features which can be attained by development of affordable and effective rhizobial inoculants that adapt to local conditions which signifies the need for functional studies using indigenous native rhizobial strains.

\section{REFERENCES:}

1. Godfray, H. C. J., Beddington, J. R., Crute, I. R., Haddad, L., Lawrence, D., Muir, J. F., \& Toulmin, C. (2010). Food security: the challenge of feeding 9 billion people. Science, (pp. 812-818).

2. Alexandratos, N., \& Bruinsma, J. (2012). World agriculture towards 2030/2050: the 2012 revision (Vol. 12, No. 3). FAO, Rome: ESA Working paper, (pp. 98-99).

3. Mahanty, T., Bhattacharjee, S., Goswami, M., Bhattacharyya, P., Das, B., Ghosh, A., \& Tribedi, P. (2017). Biofertilizers: a potential approach for sustainable agriculture development. Environmental Science and Pollution Research, (pp. 3315-3335).

4. Li, D. P., \& Wu, Z. J. (2008). Impact of chemical fertilizers application on soil ecological environment. The journal of applied ecology, (pp. 1158-1165).

5. Bhardwaj, D., Ansari, M. W., Sahoo, R. K., \& Tuteja, N. (2014). Biofertilizers function as key player in sustainable agriculture by improving soil fertility, plant tolerance and crop productivity. Microbial cell factories, (pp.

66).

6. De Araujo, A. S. F., Figueiredo, M. D. V. B., \& Monteiro, R. T. R. (2008). Potential of biological nitrogen fixation as indicator of soil pollution, In: Nitrogen Fixation Research Progress, (pp. 1-13).

7. Megali, L., Glauser, G., \& Rasmann, S. (2014). Fertilization with beneficial microorganisms 


\section{International Journal of Engineering Applied Sciences and Technology, 2019 Vol. 4, Issue 4, ISSN No. 2455-2143, Pages 141-146 \\ Published Online August 2019 in IJEAST (http://www.ijeast.com)}

decreases tomato defenses against insect pests. Agronomy for sustainable development, ( pp. 649-656).

8. Singh, J. S., Pandey, V. C., \& Singh, D. P. (2011). Efficient soil microorganisms: a new dimension for sustainable agriculture and environmental development. Agriculture, ecosystems \& environment, (pp. 339-353).

9. Matiru, V. N., \& Dakora, F. D. (2004). Potential use of rhizobial bacteria as promoters of plant growth for increased yield in landraces of

African cereal crops. African Journal of Biotechnology, 3 (1), 1-7.

10. Lhuissier, F. G. P., De Ruijter, N. C. A., Sieberer, B. J., Esseling, J. J., \& Emons, A. M. C. (2001).

Time course of cell biological events evoked in legume root hairs by Rhizobium Nod factors: state of the art. Annals of Botany, (pp.289-302).

11. Lindstrom, K., Lipsanen, P., \& Kaijalainen, S. (1990). Stability of markers used for identification of two Rhizobium galegae inoculant strains after five years in the field. Applied and environmental

microbiology, (pp. 444-450).

12. Sanginga, N., Danso, S. K. A., Mulongoy, K., \& Ojeifo, A. A. (1994). Persistence and recovery of introduced Rhizobium ten years after inoculation on Leucaena leucocephala grown on an Alfisol in southwestern Nigeria. Plant and Soil, (pp. 199-204).

13. Vessey, J. K. (2003). Plant growth promoting rhizobacteria as biofertilizers. Plant and soil, (pp. 571-586).

14. Abd-Alla, M. H. (1994). Solubilization of rock phosphates by Rhizobium and 53-56). Bradyrhizobium. Folia microbiologica, (pp.

15. Parthiban, P., AS, S. R., Mahesh, V., \& Ambikapathy, V. (2016). Studies on biosynthesis of auxin in rhizobium and their impact on growth of Vigna mungo L. Pharmaceutical and Biological Evaluations, (pp.371-376).

16. Sagolshemcha, R., Devi, Y. N., \& Singh, W. R. (2017). Plant Growth Promoting Effect and Biocontrol Potential of Rhizobium spp. against Macrophomina phaseolina.Int. J. Curr. Microbiol. App. Sci, (pp. 2695-2701).

17. Kannahi, M., \& Senbagam, N. (2014). Studies on Siderophore production by microbial isolates obtained from rhizosphere soil and its antibacterial activity. $J$ Chem Pharm Res (pp. 1142-1145)

18. Miransari, M., \& Smith, D. (2009). Rhizobial lipo- chitooligosaccharides and gibberellins enhance barley (Hordeum vulgare L.) seed germination. Biotechnology, (pp. 270-275).

19. Atzorn, R., Crozier, A., Wheeler, C. T., \& Sandberg, G. (1988). Production of gibberellins and indole-3-acetic acid by Rhizobium phaseoli in relation to nodulation of Phaseolus vulgaris roots. Planta, (pp., 532-538).

20.Glick, B. R. (2012). Plant growth-promoting bacteria: mechanisms and applications. Scientifica. 21. Bardin, S. D., Huang, H. C., Pinto, J., Amundsen, E. J., \& Erickson, R. S. (2004). Biological control of Pythium damping-off of pea and sugar beet by Rhizobium leguminosarum bv. viceae. Canadian journal of botany, (pp. 291-296).

22. Chandra, S., Choure, K., Dubey, R. C., \& Maheshwari, D. K. (2007). Rhizosphere competent Mesorhizobium loti MP6 induces root hair

curling, inhibits Sclerotinia sclerotiorum and enhances growth of Indian mustard

(Brassica campestris). Brazilian Journal of Microbiology, (pp.124-130).

23. Bhattacharyya, P. N., \& Jha, D. K. (2012). Plant growth-promoting rhizobacteria (PGPR): emergence in agriculture. World Journal of Microbiology and Biotechnology, (pp. $\quad 1327-$ 1350).

24. ÖZKOÇ, İ., \& DELIVELİ, M. H. (2001). In vitro inhibition of the mycelial growth of some root rot fungi by Rhizobium leguminosarum biovar phaseoli isolates. Turkish Journal of Biology, (pp. 435-445).

25. Siddiqui, Z. A., \& Mahmood, I. (2001). Effects of rhizobacteria and root symbionts on the reproduction of Meloidogyne javanica and growth of chickpea. Bioresource Technology, (pp. 41-45).

26. Bhagat, D., Sharma, P., Sirari, A., \& Kumawat, K. C. (2014). Screening of Mesorhizobium spp. for control of Fusarium wilt in chickpea in vitro conditions. Int J Curr Microbiol Appl Sci, (pp. 923-930).

27. Kucuk, C. (2013). In vitro antagonism of Rhizobium strains isolated from various legumes. Journal of Applied Biological Sciences, (pp. 24-30).

28. Subhani, M. N., Talib, S., Sahi, A. L., Hussain, S., Iqbal, J., \& Hussain, N. (2013). Management of chickpea wilt caused by Fusarium oxysporum sp. ciceris through antagonistic microorganisms. Canadian Journal of Plant Protection, (pp. 1-6).

29. Mishra, R. P., Singh, R. K., Jaiswal, H. K., Kumar, V., \& Maurya, S. (2006). Rhizobiummediated induction of phenolics and plant 
growth promotion in rice (Oryza sativa L.). Current microbiology, (pp. 383-389).

30. Lugtenberg, B., \& Kamilova, F. (2009). Plantgrowth-promoting rhizobacteria. Annual review of microbiology, (pp. 541-556).

31. Brigido, C., Alexandre, A., \& Oliveira, S. (2012). Transcriptional analysis of major chaperone genes in salt-tolerant and salt-sensitive mesorhizobia. Microbiological research, (pp. 623-629).

32. Yelton, M. M., Yang, S. S., Edie, S. A., \& Lim, S. T. (1983). Characterization of an effective salt-tolerant, fast-growing strain of Rhizobium japonicum. Microbiology, (pp. 15371547).

33. Bertrand, A., Dhont, C., Bipfubusa, M., Chalifour, F. P., Drouin, P., \& Beauchamp, C. J. (2015). Improving salt stress responses of the symbiosis in alfalfa using salt-tolerant cultivar and rhizobial strain. Applied Soil Ecology, (pp.108-117).

34. Qu, L., Huang, Y., Zhu, C., Zeng, H., Shen, C., Liu, C., \& Pi, E. (2016). Rhizobia-inoculation enhances the soybean's tolerance to salt stress. Plant and soil, (pp. 209-222).
35. Yura, T. (2000). The heat shock response: regulation and function. Bacterial stress responses, (pp. 3-18).

36. Alexandre, A., \& Oliveira, S. (2013). Response to temperature stress in rhizobia. Critical Reviews in Microbiology, (pp. 219-228).

37. Richardson, A. E., Simpson, R. J., Djordjevic, M. A., \& Rolfe, B. G. (1988). Expression of nodulation genes in Rhizobium leguminosarum biovar trifolii is affected by low $\mathrm{pH}$ and by $\mathrm{Ca}$ and $\mathrm{Al}$ ions. Applied and environmental microbiology, (pp. 2541-2548).

38. Mathur, S. C., \& Tannan, S. K. (1999). Future of Indian pesticides industry in next millennium. Pesticide Information, (pp. 923).

39. Aynalem, B., \& Assefa, F. (2017). Effect of Glyphosate and Mancozeb on the Rhizobia Isolated from Nodules of Vicia faba L. and on Their $\mathrm{N}_{2}$-Fixation, North Showa, Amhara Regional State, Ethiopia. Advances in Biology.

40. Bikrol, A., Saxena, N., \& Singh, K. (2005). Response of Glycine max in relation to nitrogen fixation as influenced by fungicide seed treatment. African Journal of Biotechnology, (pp. 667-671). 